\title{
Investigation of Toll-like receptors in the pathogenesis of fibrotic and granulomatous disorders: a bronchoalveolar lavage study
}

\author{
Giorgos A Margaritopoulos ${ }^{1,2}$, Katerina M Antoniou ${ }^{1,2^{*}}$, Kostas Karagiannis ${ }^{2}$, Katerina D Samara ${ }^{1,2}$, \\ Ismini Lasithiotaki ${ }^{2}$, Evi Vassalou ${ }^{2}$, Rena Lymbouridou ${ }^{2}$, Helen Koutala $^{3}$, Nikos M Siafakas ${ }^{1}$
}

\begin{abstract}
Background and aim: Toll-like receptors (TLRs), a key component of innate immunity, have recently been implicated in the pathogenesis of interstitial lung diseases (ILDs). As the involvement of TLRs has not yet been fully elucidated, the aim of the current study was to examine the expression of various TLRs in the bronchoalveolar lavage fluid (BALF) of patients with ILDs.

Patients and Methods: We studied prospectively three groups of patients: (1) one group of 35 patients with fibrotic disorders, 16 with idiopathic pulmonary fibrosis (IPF) and 19 with fibrotic interstitial pneumonias associated with collagen tissue disorders (CTD-IPs); (2) one group of 14 patients with pulmonary sarcoidosis; and (3) 11 normal subjects. We evaluated TLR expression with flow cytometry and mRNA expression with real-time PCR.

Results: An overexpression of TLR-3 mRNA was found in fibrotic disorders (CTD-IPs/IPF) in comparison with sarcoidosis (mean $\pm \mathrm{SD}, 1.104 \pm 1.087$ versus $0.038 \pm 0.03 ; P=0.04$ ). Additionally, TLR-3 mRNA was increased in CTD-IPs in comparison with IPF $(P=0.001)$, sarcoidosis $(P=0.002)$ and controls $(P=0.05)$. An upregulation in TLR-7 and -9 mRNA expression was detected in IPF $(P=0.05)$ and sarcoidosis $(P=0.05)$, respectively, when compared to controls. A higher percentage of TLR-9-expressing cells was found in BALF of CTD-IPs when compared to IPF (mean $\pm \mathrm{SD}, 36.7 \pm 7.06$ versus $14.85 \pm 3.82 ; P=0.025$ ).

Conclusion: We observed distinct profiles of TLR expression in fibrotic and granulomatous disorders. It is likely that they could play a key role in the pathogenesis of these diseases and represent future therapeutic targets.
\end{abstract}

\section{Background}

Interstitial lung diseases (ILDs) include a wide spectrum of disorders, many of which are uncommon and many of unknown etiology. Pathogenesis of idiopathic and autoimmune fibrotic lung diseases as well as granulomatous lung disorders still remains an enigma. Repetitive cycles of epithelial injury, fibroblast activation and abnormal wound repair are considered main events [1]. Several factors such as genetic and epigenetic abnormalities, infections, cytokines and growth factors, increased oxidative stress, autoantibodies, environmental exposures and gastroesophageal reflux have been suggested

\footnotetext{
* Correspondence: katerinaantoniou@yahoo.gr

'Interstitial Lung Disease Unit, Department of Thoracic Medicine, University Hospital of Heraklion, Crete, Greece

Full list of author information is available at the end of the article
}

as possible contributors for the initiation and progression of ILDs $[2,3]$.

The lungs are constantly exposed to pathogens and their byproducts and represent a frequent site of infections. Toll-like receptors (TLRs) are pattern recognition receptors that play a key role in the innate immunity, representing the first line of host defense against pathogens. TLRs localize to various cellular compartments, depending on the nature of the ligands they recognize. Thus, TLRs involved in recognition of lipid and protein ligands are expressed on the plasma membrane (TLR-1, TLR-2, TLR-4, TLR-5 and TLR-6), whereas TLRs that detect viral nucleic acids are localized in endolysosomal cellular compartments (TLR-3, TLR-7, TLR-8 and TLR-9). Endosomal TLRs recognize various conserved pathogen-associated molecular patterns (PAMPs) such

\section{() Biomed Central}


as viral derived RNA (TLR-3, -7 and -8 ) and DNA (TLR-9), as well as endogenous ligands released following tissue damage, cell death, oxidative stress and decomposition of extracellular matrix (ECM) [4-6]. TLR expression can also be detected in type II alveolar epithelial cells, airway epithelial cells, smooth muscle cells and fibroblasts [7-10]. TLR activation induces signaling pathways leading to the expression of inflammatory mediators and induction of an immune response able to eliminate the pathogen successfully. However, should this process be ineffective, the infectious stimuli persist and provoke a sustained injury, leading to chronic inflammation and skewing of the immune response from a Th1 toward a Th2 cytokine pattern, thus facilitating the development of fibrosis [11]. This has led to the hypothesis that infectious diseases could be a cofactor in the pathogenesis of ILDs.

Novel data in this field have underlined the role of TLR-9 in pulmonary fibrosis as it was shown to be overexpressed in pulmonary fibroblasts of patients with IPF [12]. Moreover, bleomycin (BLM)-induced fibrosis may be mediated by activation of TLR-2 and TLR-2 deficiency, or treatment with a TLR-2 antagonist not only protects but also reverses BLM-induced fibrosis [13]. Infections have been implicated in the pathogenesis of sarcoidosis, since DNA from mycobacteria and propionibacteria have been found in sarcoid tissue $[14,15]$. A higher expression of TLR-2 and -4 has been demonstrated in peripheral blood monocytes [16], and linkage analysis has indicated that an unidentified polymorphism of TLR-4 is associated with sarcoidosis [17]. TLRs are also implicated in the pathogenesis of autoimmune disorders such as systemic lupus erythematosus [18], rheumatoid arthritis [19-21], systemic sclerosis [22], dermatomyositis and Sjögren syndrome [23].

Our aim was to investigate whether dysfunctions of the immune system at the TLR level could elucidate these pathogenetic pathways and explain differences in prognosis between fibrotic and granulomatous disorders. Toward this purpose, we assessed the percentage of TLR-expressing cells by flow cytometry (TLR-2, -4 and $-9)$ and the mRNA expression of various TLRs $(-2,-3$, $-4,-7,-8$ and -9$)$ in the bronchoalveolar lavage fluid (BALF) of the patient group and healthy controls.

\section{Patients and Methods Patients}

Sixty (60) consecutive patients from the Interstitial Lung Disease Unit of the Department of Thoracic Medicine, University Hospital of Heraklion, were enrolled in the study: 35 patients with fibrotic disorders, 16 with idiopathic pulmonary fibrosis (IPF) and 19 with fibrotic interstitial pneumonias associated with collagen tissue disorders (CTD-IPs), 14 patients with sarcoidosis and 11 control subjects.
The ethics committee of our hospital approved the protocol, and all patients and controls gave their consent.

\section{Group A: Fibrotic Lung Disorders}

1. IPF: The diagnosis was based on internationally accepted clinical and imaging criteria [24]. In six cases, diagnosis was made by video-assisted thoracoscopic surgery (VATS), where the histologic diagnosis of usual interstitial pneumonia (UIP) was obtained. In the remaining 10 cases, the diagnosis was made on the basis of clinical and high-resolution computed tomography (HRCT) criteria: (1) bilateral basal or widespread crackles; (2) restrictive ventilatory defect or isolated reduction of $\mathrm{DL}_{\mathrm{CO}}$; (3) computed tomography $(\mathrm{CT})$ findings indicative of IPF, i.e., predominantly basal and subpleural microcystic or macrocystic honeycombing, with variably extensive ground-glass and reticular abnormalities but no consolidation, nodular abnormalities, or other parenchymal abnormalities (apart from centrilobular emphysema); and (4) no history of environmental exposure to a fibrogenic agent or connective tissue disease [24]. According to the aforementioned criteria, any known cause of pulmonary fibrosis, such as a connective tissue disorder, was excluded by both immunologic screening and rheumatological clinical evaluation.

2. CTD-IPs: The diagnosis was based on clinical and HRCT criteria in accordance with the international societies' guidelines [25-27]. In detail, the following patients were studied (1) eight patients with Rheumatoid Arthritis (RA) and HRCT characteristics of UIP; (2) seven patients with systemic sclerosis (SSc) and HRCT appearance of NSIP; (3) two patients with systemic lupus erythematous (SLE), one with HRCT features of NSIP and one with HRCT features of UIP; (4) one patient with Sjögren syndrome and histologically proven fibrotic NSIP; and (5) one patient with dermatomyositispolymyositis and HRCT features of NSIP.

\section{Group B: Sarcoidosis}

Fourteen sarcoidosis patients were enrolled in the study. Diagnosis was made according to the ATS/ERS/World Association of Sarcoidosis and Other Granulomatous Disorders joint statement [28]. All patients had transbronchial or surgical lung biopsy with histopathological evidence of noncaseating epithelioid cell granulomas without evidence of infection or inorganic material to account for the pulmonary granulomatous reaction. According to the chest radiographic classification of sarcoidosis, three patients had stage I disease (lymphadenopathy alone), five had stage II disease (lymphadenopathy and parenchymal opacities) and six had stage III disease (only parenchymal opacities). 


\section{Methods}

\section{Pulmonary function tests}

All patients were evaluated with complete pulmonary function tests (PFTs), including spirometry, measurement of lung volumes and diffusion capacity. Spirometry, lung volumes using the helium-dilution technique and $T_{\mathrm{L}}$, CO (corrected for hemoglobin) using the singlebreath technique were performed using a computerized system (Jaeger 2.12; MasterLab, Würzburg, Germany). Predicted values were obtained from the standardized lung function testing of the European Coal and Steel Community, Luxembourg (1993).

\section{BALF processing}

BALF was obtained from all patients as previously described [29]. Briefly, a flexible bronchoscope was wedged into a subsegmental bronchus of a predetermined region of interest based on radiographic findings. A BALF technique was performed by instilling a total of $240 \mathrm{~mL}$ of normal saline in $60-\mathrm{mL}$ aliquots, each retrieved by low suction. The BALF fractions were pooled and split equally into two samples. One sample was sent to the clinical microbiology and cytology laboratory, and the other sample was placed on ice and transported to the research laboratory. The research sample was filtered through sterile gauze (Thompson, Ontario, Canada) and centrifuged at $400 \mathrm{~g}$ for $15 \mathrm{~min}$ at $4^{\circ} \mathrm{C}$.

Total cell counts were determined using an improved Neubauer counting chamber and expressed as the total number of cells per millilitre of aspirated fluid. The pellet was washed three times with cold phosphate-buffered saline/Dulbecco's modified Eagle's medium, and the cells were adjusted to a final concentration of $10^{6}$ cells $/ \mathrm{mL}$ with RPMI 1640 solution plus $2 \%$ fetal calf serum. The slide preparation was performed as previously reported [30].

\section{Flow cytometric analysis}

The samples were analyzed on an Epics Elite (Coultronics, Luton, UK) fluorescence-activated flow cytometer. The white cells were tightly gated by volume and complexity on a forward $\left(0\{\mathrm{FC} 33\}^{\circ}\right)$ and side light-scattering $\left(90\{\mathrm{FC} 33\}^{\circ}\right)$ mode and by CD45+ expression (pan leukocyte marker). A minimum of $10^{5}$ cells were analyzed in each case. The appropriate control was used for subtraction of the background. The percentage of one- and two- color positive cells was measured. The following mouse antihuman monoclonal antibodies were used for labeling BALF cells: phycocyanate (Pcy-5)-conjugated anti-CD45+, phycoerythrin (PE)-conjugated anti-CD3+, fluorescein isothiocyanate (FITC)-conjugated anti-CD4+, and FITC-conjugated anti-CD8+ (Immunotech, Marseille, France). Mouse antimouse isotype-matched FITC-, PE- or PCy-5-conjugated immunoglobulin were used as control antibodies.
RNA Isolation and Reverse Transcription-Polymerase Chain Reaction: RNA extraction and reverse transcription Total RNA was extracted from each specimen using a power homogenizer and TRIzol reagent (Invitrogen, Carlsbad, CA, USA) according to the manufacturer's instructions. cDNA was synthesized using the Strascript reverse transcriptase kit (Stratagene, La Jolla, CA, USA) as previously described [31].

\section{Real-time RT-PCR}

TLR mRNA expression was measured using a real-time RT-PCR assay with SYBR-Green I. Primers were designed to span introns. $\beta$-actin was used as the internal control to normalize TLR-2, TLR-3, TLR-4, TLR-7, TLR-8 and TLR-9 (Table 1). Specifically, $1 \mu \mathrm{l}$ cDNA from all patient and control samples was amplified in a PCR reaction containing $2 \times$ Brilliant SYBR-Green I QPCR Master Mix, $300 \mathrm{nM}$ of each primer and $30 \mu \mathrm{M}$ ROX passive reference dye in a final volume of $20 \mu \mathrm{l}$. After an initial denaturation at $95^{\circ} \mathrm{C}$ for $10 \mathrm{~min}$, the samples were subjected to 40 cycles of amplification comprising denaturation at $95^{\circ} \mathrm{C}$ for $30 \mathrm{sec}$, annealing at appropriate temperature for each primer pair for $30 \mathrm{sec}$ and elongation at $72^{\circ} \mathrm{C}$ for $30 \mathrm{sec}$, followed by a melt curve analysis, in which the temperature was increased from $55^{\circ} \mathrm{C}$ to $95^{\circ} \mathrm{C}$ at a linear rate of $0.2^{\circ} \mathrm{C} / \mathrm{sec}$. Data collection was performed both during annealing and extension, with two measurements at each step, and at all times during melt curve analysis. In each PCR reaction two nontemplate controls were included. All PCR experiments were conducted on the Mx3000P real-time PCR thermal cycler using software version 2.00 Build 215, Schema 60 (Stratagene). To verify the results of the

Table 1 Primer sequences used for quantitative real-time RT-PCR

\begin{tabular}{|c|c|c|}
\hline Gene & Primer pair Sequence $\left(5^{\prime}-3^{\prime}\right)$ & $\begin{array}{c}\text { Annealing } \\
\text { temperature }\end{array}$ \\
\hline \multirow[t]{2}{*}{$T L R-2$} & For: GGGTTGAAGCACTGGACAAT & $55^{\circ} \mathrm{C}$ \\
\hline & Rev: TTCTTCCTTGGAGAGGCTGA & \\
\hline \multirow[t]{2}{*}{$T L R-3$} & For: ACACCATCTATTAAAAGACCCATTAT & $62^{\circ} \mathrm{C}$ \\
\hline & Rev: TCCAGATTTTGTTCAATAGCTTGTT & \\
\hline \multirow[t]{2}{*}{$T L R-4$} & For: GGTCACCTTTTCTTGATTCCA & $55^{\circ} \mathrm{C}$ \\
\hline & Rev: TCAGAGGTCCATCAAACATCAC & \\
\hline \multirow[t]{2}{*}{ TLR-7 } & For: GCTATCAGATTCAAAAACAACAGAA & $55^{\circ} \mathrm{C}$ \\
\hline & Rev: CACAAACACCTTTGTAGATCACTTCT & \\
\hline \multirow[t]{2}{*}{$T L R-8$} & For: GGCTITCTITCTGAAGTCAGTAGTCT & $58^{\circ} \mathrm{C}$ \\
\hline & Rev: TTCCGTGTAGTTCCAACATAGATAA & \\
\hline \multirow[t]{2}{*}{$T L R-9$} & For: CTGAGTGAGAACTTCCTCTACAAATG & $58^{\circ} \mathrm{C}$ \\
\hline & Rev: TCTITTGGTAATTGAAGGACAGGTTA & \\
\hline \multirow[t]{2}{*}{$\beta$-Actin } & For: CGGCATCGTCACCAACTG & $60^{\circ} \mathrm{C}$ \\
\hline & Rev: GGCACACGCAGCTCATTG & \\
\hline
\end{tabular}


melt curve analysis, PCR products were analyzed by electrophoresis in $2 \%$ agarose gels stained with ethidium bromide and photographed on a UV light transilluminator. Primer sequences, annealing temperatures and PCR products length for all the TLRs analyzed, as well as for $\beta$-actin are shown in Table 1. All reactions were run in triplicate, and peptide TLR transcript levels were calculated and normalized to each specimen's housekeeping gene mRNA ( $\beta$-actin) as well as the appropriate calibrators using the $\Delta \Delta \mathrm{Ct}$ method for relative quantification. Specifically, after amplification, standard curves were constructed from samples used in a series of consecutive dilutions for both the gene of interest and the internal control ( $\beta$-actin). TLRs and $\beta$-actin amplification efficiencies were the same, reaching $100 \%$. IPF and control data were first normalized against variation in sample quality and quantity. Normalized values to $\beta$-actin, $\Delta$ Cts, were initially calculated using the following equation: $\Delta \mathrm{Ct}_{\text {sample }}=\mathrm{Ct}_{\mathrm{TLRs}}-\mathrm{Ct}_{\beta}$-actin.

\section{Statistical analysis}

TLR mRNA levels and flow cytometry results were first evaluated using the one-sample Kolmogorov-Smirnov goodness of fit test to determine whether they followed a normal distribution. On the basis of the results, the nonparametric Mann-Whitney $U$ test or the parametric $t$-test was used to examine correlations. A $\chi^{2}$ test was used as indicated to examine TLR-2-3-4-7-8-9 expression status among IPF, sarcoidosis, CTD-IPs and control groups. Statistical analysis was carried out using SPSS 17.0 software (SPSS, Chicago, IL, USA). Statistical significance was set at the $95 \%$ level $(P<0.05)$.

\section{Results}

\section{Demographics}

Patients with fibrotic disorders were older than sarcoidosis patients. Female gender was more prevalent in the CTD-IPs and sarcoidosis group than in the IPF group. Most of the patients with CTD-IP were nonsmokers, whereas most of the patients of all other groups, including controls, had a current or past smoking history. A trend of significant lower forced vital capacity (FVC) in IPF in comparison with sarcoidosis patients has been observed. DLco levels indicated more severe disease in IPF patients compared to sarcoidosis and healthy controls, while CTD-IP patients had a significantly lower DLco than sarcoidosis (Table 2).

\section{Flow cytometry results}

A statistically significant difference has been found for TLR-9 expression in BALF cells of patients with CTDIPs when compared to IPF patients (mean \pm SD, $36.7 \pm$ 7.06 versus $14.85 \pm 3.82 ; P=0.025$ ) (Figures 1,2 and Table 3). Given the heterogeneity of CTD-IP group, when we compared patients with CTD-IP and HRCT features of UIP to IPF patients we found that TLR-9 expression was still significantly higher in CTD-UIP than in IPF (mean \pm SD, $34.85 \pm 6.92$ versus $14.85 \pm$ 3.82; $P=0.05$ ) (Figure 2). No significant difference has been detected in the flow cytometry results for TLR-2 or TLR-4 among the study groups.

\section{TLR MRNA expression}

TLRs mRNA expression was detectable in patients and control groups as shown in Table 4. TLR-3 mRNA

Table 2 Demographic and lung function characteristics of patient groups

\begin{tabular}{|c|c|c|c|c|c|}
\hline Characteristics & Controls & IPF & CTD-IP & SARC & $P$ value \\
\hline Number & 11 & 16 & 16 & 14 & - \\
\hline $\mathrm{Age}^{*}$ & $58.44 \pm 3.49$ & $67.27 \pm 1.62$ & $64.23 \pm 4.29$ & $47.42 \pm 4.65$ & p2:0.001 p3:0.04 p4:0.01 \\
\hline $\begin{array}{l}\text { Gender: } \\
\text { (male/female)** }\end{array}$ & $8 / 3$ & $12 / 4$ & $3 / 13$ & $5 / 9$ & $\begin{array}{l}\mathrm{p} 1:<10^{-4} \mathrm{p} 2: 0.02 \\
\mathrm{p} 5: 0.002 \\
\mathrm{p} 6: 0.04\end{array}$ \\
\hline Nonsmokers** & 3 & 6 & 14 & 5 & p1: 0.00 p4:0.004 p5:0.001 \\
\hline Smokers** & 7 & 1 & 1 & 4 & p3:0.001 p5:0.001 \\
\hline Ex-smokers** & 1 & 9 & 1 & 5 & p1:0.003 p3:0.02 \\
\hline FEV1* & $85.11 \pm 7.89$ & $82.44 \pm 6.15$ & $86.93 \pm 6.37$ & $89.83 \pm 6.96$ & NS \\
\hline $\mathrm{FVC}^{*}$ & $91.56 \pm 7.46$ & $76.06 \pm 5.23$ & $81.07 \pm 5.65$ & $91.75 \pm 5.97$ & p2:0.06 \\
\hline $\mathrm{FEV}_{1 / \mathrm{FVC}^{*}}$ & $74.56 \pm 4.48$ & $85.14 \pm 2.76$ & $85.36 \pm 2.57$ & $81.36 \pm 2.63$ & p5:0.057 \\
\hline DLCO* & $76.22 \pm 7.72$ & $54.19 \pm 7.18$ & $60.15 \pm 5.12$ & $91.3 \pm 8.06$ & p2:0.002 p3:0.05 p4:0.005 \\
\hline $\mathrm{KCO}^{*}$ & $86.22 \pm 8.14$ & $87.63 \pm 6.44$ & $79 \pm 6.92$ & $108.9 \pm 5.91$ & p2:0.02 p4:0.003 p6:0.04 \\
\hline
\end{tabular}

Values are expressed as means \pm SEM (standard error of the mean).

${ }^{*} t$-test; $P<0.05$ is considered statistically significant.

${ }^{*} \chi^{2}$ test; $P<0.05$ is considered statistically significant.

NS, not significant.

Abbreviations: FEV1: forced expiratory volume in one second, FVC: forced vital capacity, TLC: total lung capacity, $\mathrm{DL}_{\mathrm{co}}$, diffusing capacity for carbon monoxide, KCO: DLCO per unit lung volume. p1: $P$ value between IPF and CTD-IPs, p2: $P$ value between IPF and sarcoidosis, p3: $P$ value between IPF and control, p4: $P$ value between CTD-IP and sarcoidosis, p5: $P$ value between CTD-IP and control, p6: $P$ value between sarcoidosis and control. 

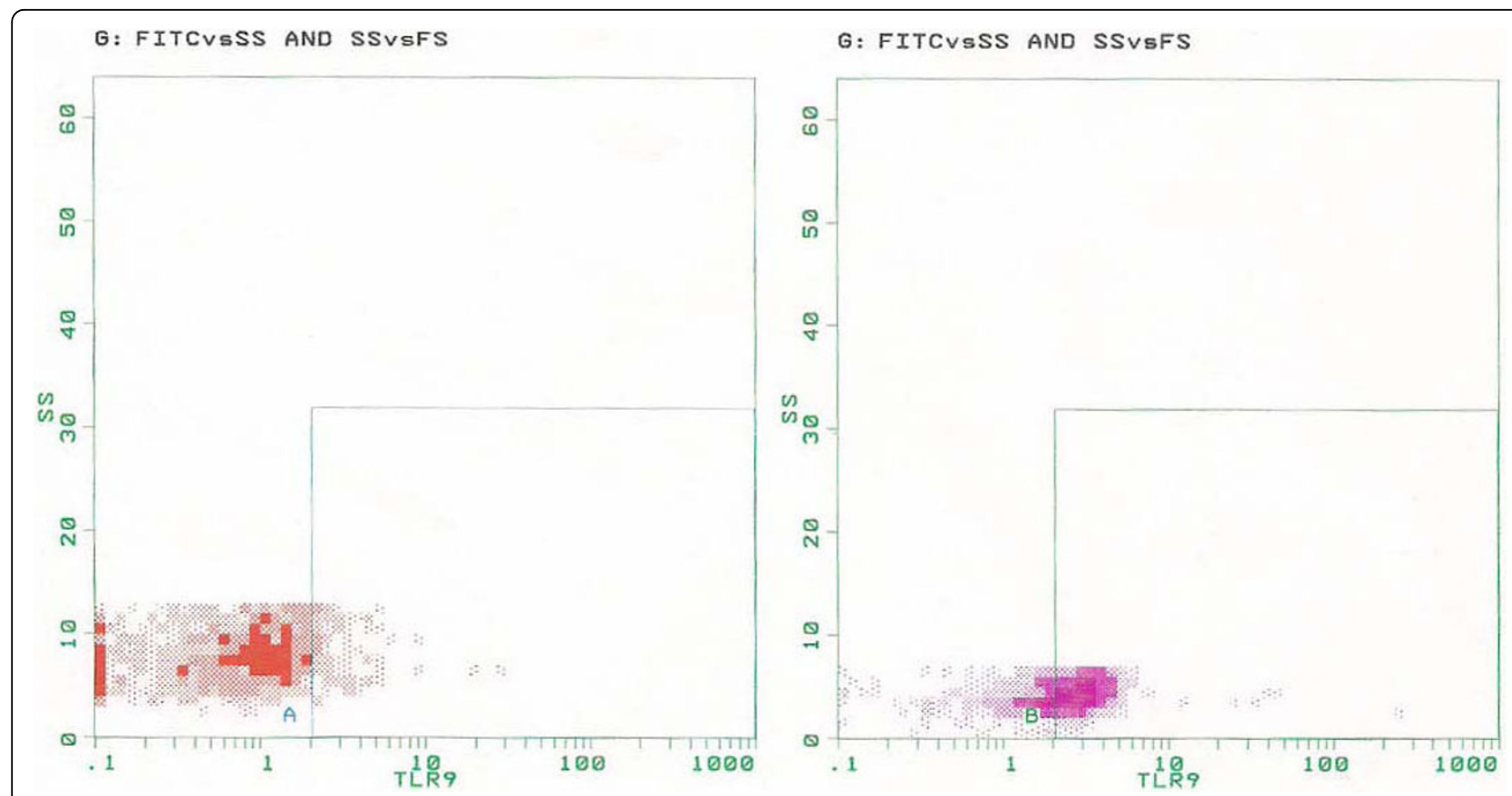

Figure 1 Expression of Toll-like receptor (TLR)-9 in bronchoalveolar lavage fluid (BALF) cells in one representative patient with idiopathic pulmonary fibrosis (IPF) (right) and one with fibrotic interstitial pneumonias associated with collagen tissue disorders (CTDIP) (left).

expression was significantly higher in patients with fibrotic disorders (CTD-IPs and IPF) when compared to those with granulomatous disorders (sarcoidosis) (mean $\pm \mathrm{SD}, 1.104 \pm 1,087$ versus $0.038 \pm 0.037 ; P=$ $0.04)$. In addition, TLR-3 mRNA expression was significantly higher when we compared patients with CTDIP to IPF (mean \pm SD, $2.03 \pm 2$ versus $0.007 \pm 0.005$; $P=0.001)$. When we compared patients with CTD-IP and HRCT features of UIP to IPF patients, we found that TLR-3 mRNA expression was still significantly higher in CTD-UIP than in IPF (mean \pm SD, $3.847 \pm$ 3.804 versus $0.007 \pm 0.005 ; P=0.002$ ). Moreover, patients with CTD-IP had an increased TLR-3 mRNA expression in comparison with sarcoidosis (mean \pm SD, $2.03 \pm 2$ versus $0.038 \pm 0.037 ; P=0.002$ ) and control subjects (mean $\pm \mathrm{SD}, 2.03 \pm 2$ versus $0.0014 \pm$ 0.0008; $P=0.05$ ) (Table 5 and Figure 3). Moreover, TLR-7 mRNA expression was increased in patients
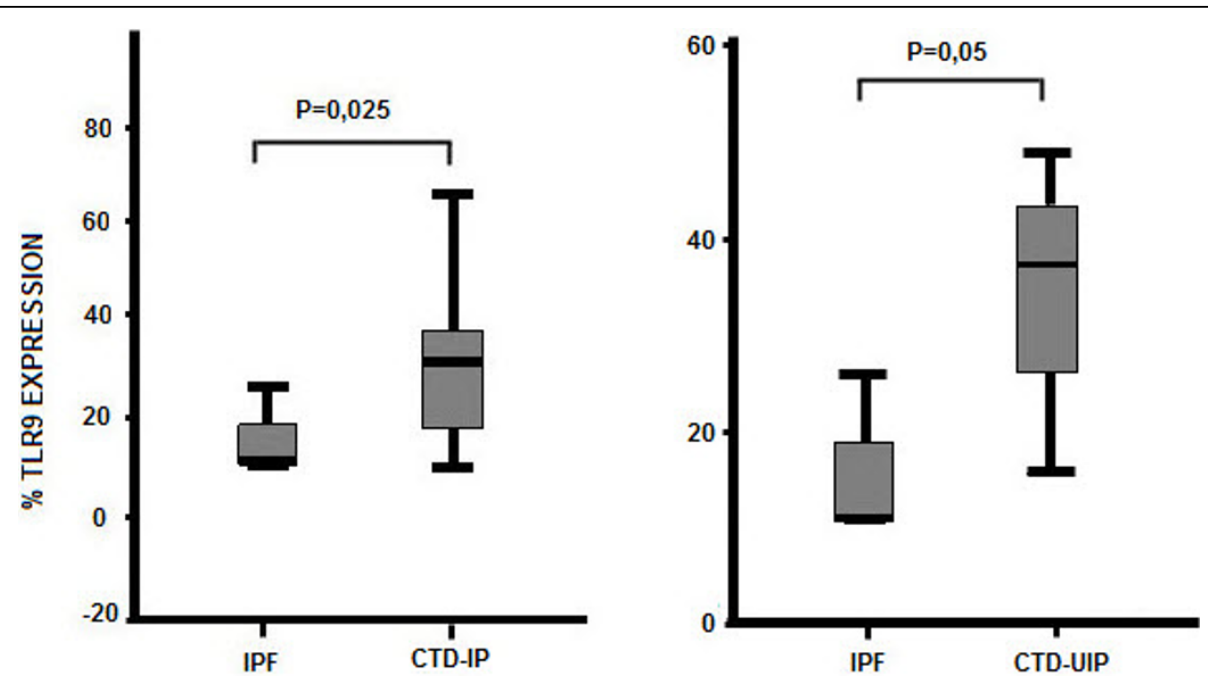

Figure 2 Expression of TLR-9 in BALF cells of patients with IPF, CTD-IP and CTD-UIP. 
Table 3 Flow cytometry results

\begin{tabular}{cccccl}
\hline & IPF & CTD-IP & Sarcoidosis & Controls & $P$ value \\
\hline TLR-2 & $18.4 \pm 13.27$ & $3.12 \pm 0.96$ & $3.23 \pm 1.31$ & $4.22 \pm 1$ & NS \\
TLR-4 & $32.45 \pm 5.41$ & $38.52 \pm 4.94$ & $28.06 \pm 6.34$ & $29.3 \pm 8.15$ & NS \\
TLR-9 & $14.85 \pm 3.82$ & $36.7 \pm 7.06$ & $27 \pm 6.72$ & $36.8 \pm 10.26$ & p1:0.025
\end{tabular}

Values are expressed as the mean \pm SEM (standard error of the mean). MannWhitney $U$ test; $P<0.05$ is considered statistically significant. NS, not significant. p1: $P$ value between IPF and CTD-IPs, p2: $P$ value between IPF and sarcoidosis, $\mathrm{p3}: P$ value between IPF and control, $\mathrm{p} 4: P$ value between CTD-IP and sarcoidosis, p5: $P$ value between CTD-IP and control, p6: $P$ value between sarcoidosis and control.

with IPF when compared to control group (mean \pm SD, $5.06 \pm 4.12$ versus $1.5 \pm 1.35 ; P=0.05$ ) (Table 5). TLR-9 mRNA expression was marginally increased in patients with sarcoidosis when compared to healthy subjects (mean $\pm \mathrm{SD}, 213.52 \pm 211.95$ versus $0.58 \pm$ $0.53 ; P=0.05$ ) (Table 5). No statistically significant difference has been detected at the mRNA expression of TLR-2-4-8 among patient groups and control subjects (Table 5).

Furthermore, we explored the impact of smoking in TLRs mRNA expression. For this reason, we divided the patients of each group (IPF, CTD-IP, sarcoidosis) into two subgroups, the first one composed of current and ex-smokers and the second one composed of nonsmokers. We correlated the expression of TLRs with cigarette smoking. We have not found any significant difference in TLR expression between these two subgroups in our patient groups.

\section{Discussion}

To the best of our knowledge, this is the first attempt to demonstrate that TLRs are implicated in the pathogenesis of fibrotic and granulomatous lung disorders, using BALF, a minimally invasive, useful tool in the everyday diagnostic workup of interstitial lung diseases.

We observed an overexpression of TLR-3 mRNA in patients with fibrotic lung disorders (IPF and CTD-IP) versus patients with nonfibrotic sarcoidosis, suggesting that different activity of this receptor could be one of the mechanisms able to explain the skew toward the Th2 cytokine pattern which characterizes the development of fibrosis. Recently, our study group has proposed distinct angiogenic profiles between IPF and sarcoidosis as another possible mechanism for the development of fibrosis [29,32]. A link between TLR activation and angiogenesis has been observed in patients with Crohn's disease, where activation of TLRs located in gut myofibroblast results in an increased secretion of CXC chemokine ligand 8 (CXCL8), which is a potent angiogenetic factor implicated in the development of fibrosis $[33,34]$.

We also detected an overexpression of TLR-3 mRNA in CTD-IP samples in comparison with IPF. Moreover, knowing that CTD-IPs are a heterogeneous group of diseases, we compared patients with IPF to patients with CTD-IP and radiologic pattern of UIP. We observed upregulation of TLR-3 activity when the UIP pattern is associated with CTDs compared with IPF. It is well known that interstitial pneumonias have a better prognosis when associated with CTDs than in their idiopathic forms, even when they exhibit the same histopathologic pattern [35], reflecting probably distinct pathogenetic pathways. The overexpression of TLR-3 in CTD-IP and CTD-UIP patients could be implicated in this phenomenon. Furthermore, using flow cytometry, TLR-9 was found to be overexpressed in BALF cells of patients with CTD-IP as well as CTD-UIP when compared to IPF. We have recently suggested that an upregulation of angiogenesis in CTD-IPs in comparison with IPF could also be a plausible explanation [36]. Additionally, an overexpression of TLR-7 mRNA in patients with IPF versus healthy subjects was shown, enhancing the possible role of TLRs in the pathogenesis of fibrotic disease.

TLR-3, -7 and -9 , all recognizing endosomal ligands, are implicated in the innate immunity, recognizing viral derived RNA and DNA, respectively [7]. Viral infections are thought to represent cofactors in the pathogenesis of autoimmune and idiopathic lung fibrosis. EpsteinBarr virus (EBV) has been isolated from lung tissue of

Table 4 Expression profile of TLR mRNA in patient group and control subjects

\begin{tabular}{|c|c|c|c|c|c|}
\hline & IPF & CTD-IP & SARCOIDOSIS & CONTROLS & $P$ value \\
\hline TLR-2 & $100(16 / 16)$ & $94.7(18 / 19)$ & $100(14 / 14)$ & $88.9(8 / 9)$ & NS \\
\hline TLR-3 & $12.5(2 / 16)$ & $78.94(15 / 19)$ & $14.3(2 / 14)$ & $33.3(3 / 9)$ & $\begin{array}{l}\mathrm{p} 1:<10^{-4} \mathrm{p} 4:<10^{-4} \\
\text { p5:0.01 }\end{array}$ \\
\hline TLR-4 & $93.75(15 / 16)$ & $89.4(17 / 19)$ & $85.7(12 / 14)$ & $77.7(7 / 9)$ & NS \\
\hline TLR-7 & $93.75(15 / 16)$ & $94.7(18 / 19)$ & $100(14 / 14)$ & $77.7(7 / 9)$ & NS \\
\hline TLR-8 & $100(16 / 16)$ & $100(19 / 19)$ & $92.9(13 / 14)$ & $100(9 / 9)$ & NS \\
\hline TLR-9 & $100(16 / 16)$ & $100(19 / 19)$ & $92.9(13 / 14)$ & $77.7(7 / 9)$ & $\begin{array}{l}\text { p3:0.04 } \\
\text { p5:0.03 }\end{array}$ \\
\hline
\end{tabular}

$\chi^{2}$ test; $P<0.05$ is considered statistically significant. NS, not significant. $p 1: P$ value between IPF and CTD-IPs, p2: $P$ value between IPF and sarcoidosis, p3: $P$ value between IPF and control, p4: $P$ value between CTD-IP and sarcoidosis, p5: $P$ value between CTD-IP and control, p6: $P$ value between sarcoidosis and control. 
Table 5 mRNA expression of TLRs in patient group and control subjects

\begin{tabular}{|c|c|c|c|c|c|}
\hline & IPF & CTD-IP & Sarcoidosis & Controls & $P$ value \\
\hline TLR-2 & $9.75 \pm 7.54$ & $4.04 \pm 3.53$ & $599.9 \pm 597.7$ & $1.72 \pm 1.63$ & NS \\
\hline TLR-3 & $0.007 \pm 0.005$ & $2.03 \pm 2$ & $0.038 \pm 0.037$ & $0.0014 \pm 0.0008$ & $\begin{array}{l}\text { p1:0.001 } \\
\text { p4:0.002 } \\
\text { p5:0.00 }\end{array}$ \\
\hline TLR-4 & $2.34 \pm 1.61$ & $1.35 \pm 1.12$ & $20.98 \pm 19.3$ & $12.37 \pm 12.24$ & NS \\
\hline TLR-7 & $5.06 \pm 4.12$ & $12.92 \pm 10.25$ & $29 \pm 26.81$ & $1.5 \pm 1.35$ & p3:0.05 \\
\hline TLR-8 & $11.14 \pm 7.89$ & $14.5 \pm 11.65$ & $679.33 \pm 672.34$ & $8.67 \pm 8.51$ & NS \\
\hline TLR-9 & $3.1 \pm 2.51$ & $1.54 \pm 0.94$ & $213.52 \pm 211.95$ & $0.58 \pm 0.53$ & p6:0.05 \\
\hline
\end{tabular}

Values are expressed as means \pm SEM (standard error of the mean). Mann-Whitney $U$ test; $P<0.05$ is considered statistically significant. NS, not significant. p1: $P$ value between IPF and CTD-IPs, p2: $P$ value between IPF and sarcoidosis, $\mathrm{p} 3: P$ value between IPF and control, p4: $P$ value between CTD-IP and sarcoidosis, p5: $P$ value between CTD-IP and control, p6: $P$ value between sarcoidosis and control.

patients with IPF and scleroderma-associated fibrosis [37] and serum complement fixation titers of cytomegalovirus (CMV) were elevated in IPF and CTD-IPs [38], whereas human herpes virus -7 and -8 have also been detected in IPF [39]. Recent data have shown that TLR9 is upregulated in IPF [12]; thus it is likely that viral infections via activation of TLR-9 could have a key role in the pathogenesis of IPF as well as in the acute exacerbation of the disease observed after an infection. On the other hand, there are no data in the current literature regarding TLR involvement in the pathogenesis of autoimmune lung fibrosis. However, it has been demonstrated that TLRs are involved in the pathogenesis of CTDs via activation through endogenous ligands released during infections [40]. TLR-3 and -9 are expressed in human synovial tissue from RA patients [19-21] and in peripheral blood cells in active systemic lupus erythematosus [18]. Our data demonstrate an increased expression of TLR-3 and -9 in CTD-IPs compared to IPF, suggesting that endosomal TLRs could be a reliable marker in the differentiation of autoimmune from idiopathic fibrosis.
We have also tried to find out if cigarette smoking has some impact on TLR expression. It is of note now that smoking is involved in the pathogenesis of pulmonary fibrosis and influences the outcome [41]. Moreover, smoking and other environmental agents also have a negative effect on innate immunity and various cancers [42]. It has been observed that the expression of TLR-2 and -4 in alveolar macrophage of smokers in response to their ligands is decreased compared to nonsmokers [43]. Additionally, infants of smoking mothers had a significantly attenuated innate TLR-mediated response compared with infants of nonsmokers in monocytes [44]. We have not found any difference in TLR expression when we subdivided the patients of each one of the patient groups into smokers (former and current) and nonsmokers.

However, there are some limitations that need to be addressed. We used BALF to evaluate the activity of TLRs instead of lung tissue. Lung tissue is not warranted for the diagnosis of CTD-IPs, as it does not add information regarding the prognosis of the disease [35] and diagnosis of IPF can be based on imaging findings

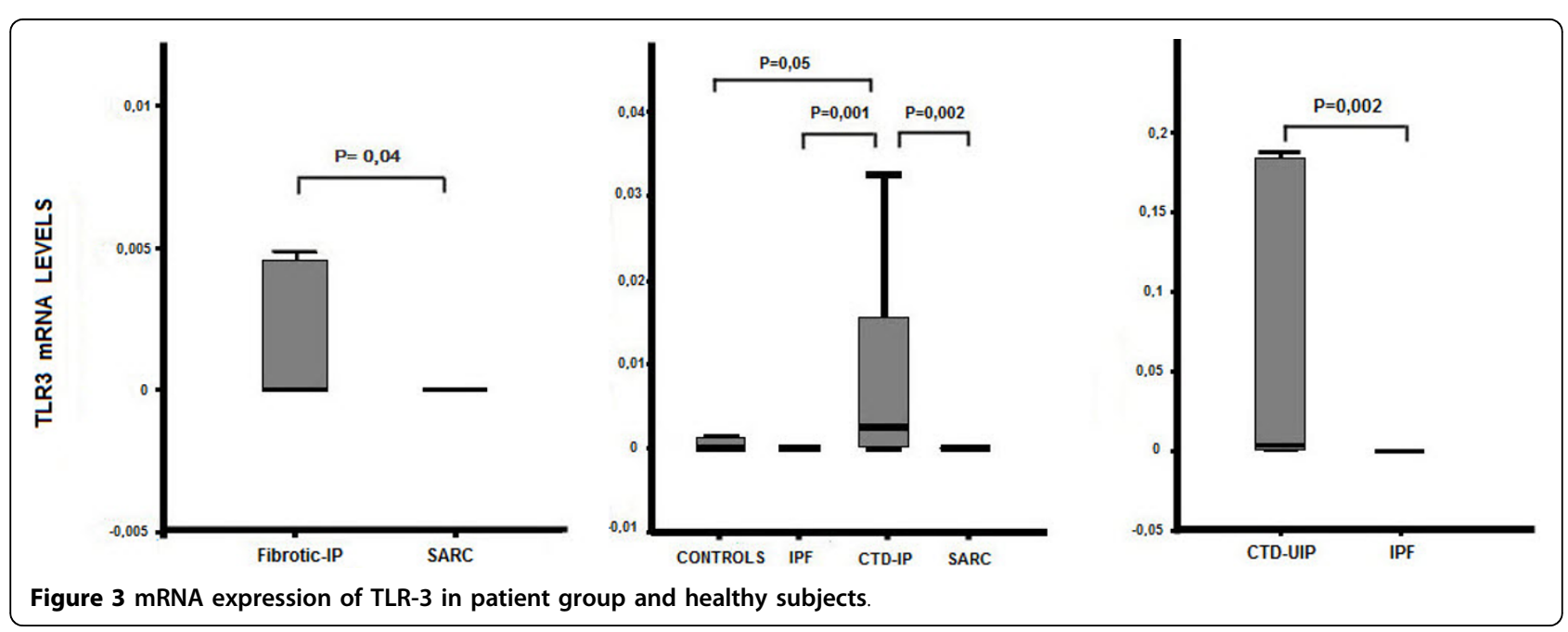


alone, with the exception of cases exhibiting unusual HRCT findings [24].

\section{Conclusion}

In conclusion, we have demonstrated that dysfunctions of the innate immune system at the TLR level could be implicated in the pathogenesis of fibrotic and granulomatous disorders. TLRs could represent a novel therapeutic target for these disorders and in particular for the most devastating form of fibrosis, IPF. However, further studies are needed to better understand the pathogenetic mechanisms of these complicated diseases.

\section{Acknowledgements}

We are grateful to Nikos Tzanakis and Irini Lambiri for performing the bronchoscopies and the bronchoalveolar lavage.

\section{Author details}

'Interstitial Lung Disease Unit, Department of Thoracic Medicine, University Hospital of Heraklion, Crete, Greece. ${ }^{2}$ Laboratory of Molecular and Cellular Pulmonary Medicine, Medical School, University of Crete, Greece. ${ }^{3}$ Laboratory of Hematology, Medical School, University of Crete, Greece.

\section{Authors' contributions}

GM: participated in the design of the study and wrote the manuscript, KK: carried out the flow cytometry and carried out the real-time-PCR, KDS: helped to draft the manuscript, IL, EV, RL: participated in the sequence alignment and carried out the real-time-PCR, RL: performed the statistical analysis, HK: carried out the flow cytometry, NMS and KMA: participated in conception, coordination and design of the study and helped to draft the manuscript.

\section{Competing interests}

The authors declare that they have no competing interests.

Received: 16 June 2010 Accepted: 11 October 2010

Published: 11 October 2010

\section{References}

1. Selman M, Pardo A: The epithelial/fibroblastic pathway in the pathogenesis of idiopathic pulmonary fibrosis. Am J Respir Cell Mol Biol 2003, 29:593-597.

2. Kottmann RM, Hogan CM, Phipps RP, Sime PJ: Determinants of initiation and progression of idiopathic pulmonary fibrosis. Respirology 2009, 14:917-933.

3. Iannuzzi MC, Rybicki BA, Teirstein AS: Sarcoidosis. N Engl J Med 2007, 357:2153-2165.

4. Tsan MF, Gao B: Endogenous ligands of Toll-like receptors. J Leukoc Biol 2004, 76:514-519.

5. Bianchi ME: DAMPs, PAMPs and alarmins: all we need to know about danger. J Leukoc Biol 2007, 81:1-5.

6. Wagner $\mathrm{H}$ : Endogenous TLR ligands and autoimmunity. Adv Immunol 2006, 91:159-173.

7. Akira S, Takeda K: Toll-like receptor signalling. Nat Rev Immunol 2004 4:499-511.

8. Droemann D, Goldmann T, Branscheid D, Clark R, Dalhoff K, Zabel P, Vollmer E: Toll-like receptor 2 is expressed by alveolar epithelial cells type II and macrophages in the human lung. Histochem Cell Biol 2003, 119:103-108.

9. Morris GE, Whyte MK, Martin GF, Jose PJ, Dower SK, Sabroe I: Agonists of toll-like receptors 2 and 4 activate airway smooth muscle via mononuclear leukocytes. Am J Respir Crit Care Med 2005, 171:814-822.

10. Greene CM, Carroll TP, Smith SG, Taggart CC, Devaney J, Griffin S, O'Neill SJ, McElvaney NG: TLR-induced inflammation in cystic fibrosis and noncystic fibrosis airway epithelial cells. J Immunol 2005, 174:1638-1646.
11. Meneghin A, Hogaboam CM: Infectious disease, the innate immune response, and fibrosis. J Clin Invest 2007, 117:530-538.

12. Meneghin A, Choi ES, Evanoff HL, Kunkel SL, Martinez FJ, Flaherty KR, Toews GB, Hogaboam CM: TLR9 is expressed in idiopathic interstitial pneumonia and its activation promotes in vitro myofibroblast differentiation. Histochem Cell Biol 2008, 130:979-992.

13. Yang HZ, Cui B, Liu HZ, Chen ZR, Yan HM, Hua F, Hu ZW: Targeting TLR2 attenuates pulmonary inflammation and fibrosis by reversion of suppressive immune microenvironment. J Immunol 2009, 182:692-702.

14. Saboor SA, Johnson NM, McFadden J: Detection of mycobacterial DNA in sarcoidosis and tuberculosis with polymerase chain reaction. Lancet. 1992, 339:1012-1015.

15. Abe C, Iwai K, Mikami R, Hosoda Y: Frequent isolation of Propionibacterium acnes from sarcoidosis lymph nodes. Zentralbl Bakteriol Mikrobiol Hyg A 1984, 256:541-547.

16. Wikén $M$, Grunewald J, Eklund A, Wahlström J: Higher monocyte expression of TLR2 and TLR4, and enhanced pro-inflammatory synergy of TLR2 with NOD2 stimulation in sarcoidosis. J Clin Immunol 2009, 29:78-89.

17. Schürmann M, Kwiatkowski R, Albrecht M, Fischer A, Hampe J, MüllerQuernheim J, Schwinger E, Schreiber S: Study of Toll-like receptor gene loci in sarcoidosis. Clin Exp Immunol 2008, 152:423-431.

18. Papadimitraki ED, Choulaki C, Koutala E, Bertsias G, Tsatsanis C, Gergianaki I, Raptopoulou A, Kritikos HD, Mamalaki C, Sidiropoulos P, Boumpas DT: Expansion of toll-like receptor 9-expressing B cells in active systemic lupus erythematosus: implications for the induction and maintenance of the autoimmune process. Arthritis Rheum 2006, 54:3601-3611.

19. Brentano F, Schorr O, Gay RE, Gay S, Kyburz D: RNA released from necrotic synovial fluid cells activates rheumatoid arthritis synovial fibroblasts via Toll-like receptor 3. Arthritis Rheum 2005, 52:2656-2665.

20. Roelofs MF, Joosten LA, Abdollahi-Roodsaz S, van Lieshout AW, Sprong T, van den Hoogen FH, van den Berg WB, Radstake TR: The expression of toll-like receptors 3 and 7 in rheumatoid arthritis synovium is increased and costimulation of Toll-like receptors 3,4 , and $7 / 8$ results in synergistic cytokine production by dendritic cells. Arthritis Rheum 2005, 52:2313-2322.

21. Kyburz D, Rethage J, Seibl R, Lauener R, Gay RE, Carson DA, Gay S: Bacterial peptidoglycans but not $\mathrm{CpG}$ oligodeoxynucleotides activate synovial fibroblasts by toll-like receptor signaling. Arthritis Rheum 2003, 48:642-650.

22. Lafyatis $R$, York M: Innate immunity and inflammation in systemic sclerosis. Curr Opin Rheumatol 2009, 21:617-622.

23. Baechler EC, Batliwalla FM, Reed AM, Peterson EJ, Gaffney PM, Moser KL, Gregersen PK, Behrens TW: Gene expression profiling in human autoimmunity. Immunol Rev 2006, 210:120-137.

24. American Thoracic Society/European Respiratory Society International: Multidisciplinary Consensus Classification of the Idiopathic Interstitial Pneumonias. Am J Respir Crit Care Med 2002, 165:277-304.

25. Park JH, Kim DS, Park IN, Jang SJ, Kitaichi M, Nicholson AG, Colby TV: Prognosis of fibrotic interstitial pneumonia: idiopathic versus collagen vascular disease-related. Am J Respir Crit Care Med 2007, 175:705-711.

26. American Rheumatism Association Diagnostic and Therapeutic Criteria Subcommittee for Scleroderma: Criteria of the American Rheumatism Association Diagnostic and Therapeutic Criteria Committee: preliminary criteria for the classification of systemic sclerosis (scleroderma). Arthritis Rheum 1988, 23:581-590.

27. Arnett FC, et al: The American Rheumatism Association 1987 revised criteria for the classification of rheumatoid arthritis. Arthritis Rheum 1988, 31:315-324.

28. Hunninghake GW, Costabel U, Ando M, Baughman R, Cordier JF, du Bois R, Eklund A, Kitaichi M, Lynch J, Rizzato G, Rose C, Selroos O, Semenzato G, Sharma OP: ATS/ERS/WASOG statement on sarcoidosis. American Thoracic Society/European Respiratory Society/World Association of Sarcoidosis and Granulomatous Disorders. Sarcoidosis Vasc Diffuse Lung Dis 1999, 16:149-173.

29. Antoniou KM, Tzouvelekis A, Alexandrakis MG, Sfiridaki K, Tsiligianni I, Rachiotis G, Tzanakis N, Bouros D, Milic-Emili J, Siafakas NM: Different angiogenic activity in pulmonary sarcoidosis and idiopathic pulmonary fibrosis. Chest 2006, 130:982-988.

30. Haslam PL, Baughman RP: Report of ERS Task Force: guidelines for measurement of acellular components and standardization of BAL. Eur Respir J 1999, 14:245-248. 
31. Soulitzis N, Karyotis I, Delakas D, Spandidos DA: Expression analysis of peptide growth factors VEGF, FGF2, TGFB1, EGF and IGF1 in prostate cancer and benign prostatic hyperplasia. Int J Oncol 2006, 29:305-314.

32. Antoniou KM, Soufla G, Proklou A, Margaritopoulos G, Choulaki C, Lymbouridou R, Samara KD, Spandidos DA, Siafakas NM: Different activity of the biological axis VEGF-Flt-1 (fms-like tyrosine kinase 1) and CXC chemokines between pulmonary sarcoidosis and idiopathic pulmonary fibrosis: a bronchoalveolar lavage study. Clin Dev Immunol 2009, 2009:537929.

33. Otte $J M$, Rosenberg IM, Podolsky DK: Intestinal myofibroblasts in innate immune responses of the intestine. Gastroenterology 2003, 124:1866-1878.

34. Keane MP, Arenberg DA, Lynch JP 3rd, Whyte Rl, lannettoni MD, Burdick MD, Wilke CA, Morris SB, Glass MC, DiGiovine B, Kunkel SL, Strieter RM: The CXC chemokines, IL-8 and IP-10, regulate angiogenic activity in idiopathic pulmonary fibrosis. J Immunol 1997, 159:1437-1443.

35. Antoniou KM, Margaritopoulos G, Economidou F, Siafakas NM: Pivotal clinical dilemmas in collagen vascular diseases associated with interstitial lung involvement. Eur Respir 」 2009, 33:882-896.

36. Margaritopoulos GA, Antoniou KM, Soufla G, Karagiannis K, Proklou A, Lasithiotaki I, Tzanakis N, Spandidos DA, Siafakas NM: Upregulation of stromal cell derived factor-1alpha in collagen vascular diseasesassociated interstitial pneumonias (CVDs-IPs). Pulm Pharmacol Ther 2010, 23:115-120.

37. Tsukamoto K, Hayakawa H, Sato A, Chida K, Nakamura H, Miura K: Involvement of Epstein-Barr virus latent membrane protein 1 in disease progression in patients with idiopathic pulmonary fibrosis. Thorax 2000, 55:958-961.

38. Yonemaru M, Kasuga I, Kusumoto H, Kunisawa A, Kiyokawa H, Kuwabara S, Ichinose $Y$, Toyama K: Elevation of antibodies to cytomegalovirus and other herpes viruses in pulmonary fibrosis. Eur Respir J 1997, 10:2040-2045.

39. Tang YW, Johnson JE, Browning PJ, Cruz-Gervis RA, Davis A, Graham BS, Brigham KL, Oates JA Jr, Loyd JE, Stecenko AA: Herpesvirus DNA is consistently detected in lungs of patients with idiopathic pulmonary fibrosis. J Clin Microbiol 2003, 41:2633-2640.

40. Searle J, Kerr JF, Bishop CJ: Necrosis and apoptosis: distinct modes of cell death with fundamentally different significance. Pathol Annu 1982, 17(Pt 2):229-259.

41. Antoniou KM, Hansell DM, Rubens MB, Marten K, Desai SR, Siafakas NM, Nicholson AG, du Bois RM, Wells AU: Idiopathic pulmonary fibrosis: outcome in relation to smoking status. Am J Respir Crit Care Med 2008, 177:190-194

42. Symvoulakis EK, Zaravinos A, Panutsopulos D, Zoras O, Papalambros E, Sigala F, Spandidos DA: Highly conserved sequence of exon 15 BRAF gene and KRAS codon 12 mutation among Greek patients with colorectal cancer. Int J Biol Markers 2007, 22:12-18.

43. Droemann D, Goldmann T, Tiedje T, Zabel P, Dalhoff K, Schaaf B: Toll-like receptor 2 expression is decreased on alveolar macrophages in cigarette smokers and COPD patients. Respir Res 2005, 6:68.

44. Noakes PS, Hale J, Thomas R, Lane C, Devadason SG, Prescott SL: Maternal smoking is associated with impaired neonatal toll-like-receptormediated immune responses. Eur Respir J 2006, 28:721-729.

doi:10.1186/1755-1536-3-20

Cite this article as: Margaritopoulos et al.: Investigation of Toll-like receptors in the pathogenesis of fibrotic and granulomatous disorders: a bronchoalveolar lavage study. Fibrogenesis \& Tissue Repair 2010 3:20.

\section{Submit your next manuscript to BioMed Central and take full advantage of:}

- Convenient online submission

- Thorough peer review

- No space constraints or color figure charges

- Immediate publication on acceptance

- Inclusion in PubMed, CAS, Scopus and Google Scholar

- Research which is freely available for redistribution

Submit your manuscript at www.biomedcentral.com/submit 